\title{
Smooth Surface with U-grooved Structures for Light-detecting Area of Photodetectors Using Dual-doped Tetramethyl Ammonium Hydroxide
}

\author{
Kamonwan Suttijalern and Surasak Niemcharoen* \\ Department of Electronics Engineering, School of Engineering, King Mongkut's Institute of \\ Technology Ladkrabang, Chalongkrung Road, Ladkrabang, Bangkok 10520, Thailand
}

(Received May 15, 2021; accepted September 1, 2021)

Keywords: U-grooved structure, anisotropic etching, oxidizing agent, smooth surface, silicon photodetectors

Micro-electromechanical system (MEMS) fabrication has gained popularity as a means of etching silicon substrates. This paper discusses the surface texturization of a U-grooved structure by a very simple and cost-effective technique for use as a U-grooved metalsemiconductor-metal (UMSM) photodetector with aluminum $/ \mathrm{n}-\mathrm{Si} /$ aluminum materials. A series of etching experiments were carried out involving the addition of ammonium peroxodisulfate $\left[\left(\mathrm{NH}_{4}\right)_{2} \mathrm{SO}_{4}\right]$ at different concentrations to tetramethyl ammonium hydroxide (TMAH)/silicic acid etching solution, also called dual-doped TMAH. It was found that the addition of $11.5 \mathrm{~g} / 1\left(\mathrm{NH}_{4}\right)_{2} \mathrm{SO}_{4}$ to TMAH/silicic acid enhances the smoothness of the surface and prevents the unwanted etching of exposed aluminum. We utilized dual-doped TMAH in the fabrication of a nanostructure in a U-grooved photodetector and found that the U-grooved photodetector has a $\sim 59 \%$ higher photocurrent than that of a planar photodetector. The U-grooved photodetector demonstrates that increasing the light-detecting area results in high photocurrent performance for high-efficiency optical devices.

\section{Introduction}

Semiconductor inventions have been widely developed and are now highly advanced, enabling high-speed performance so that systems may immediately respond, have low power consumption, and be used with mobile devices. Micro-electromechanical system (MEMS) is a process technology used to create tiny integrated devices or systems that combine mechanical and electrical components, leading to higher packaging density. ${ }^{(1-3)}$ Anisotropic etching is an integral part of MEMS fabrication, which is used to transform the microsurface structure of a device into a circuit pattern or to etch materials that are difficult to remove from the device. ${ }^{(4-6)}$ The etchants used in anisotropic etching have unequal etching selectivity between the various crystal surfaces. As a result, the groove formed by the etching has the geometry of a U-groove. Silicon has a very high anisotropic etching rate, and only certain solutions can be used for the anisotropic wet etching of silicon. For example, potassium hydroxide $(\mathrm{KOH})$ is a nontoxic

*Corresponding author: e-mail: surasuk.ni@kmitl.ac.th https://doi.org/10.18494/SAM.2021.3432 
etchant with a moderate $\mathrm{Si} / \mathrm{SiO}_{2}$ etching rate ratio and a high silicon etching rate. However, $\mathrm{KOH}$ is not compatible with CMOS processes due to potassium ion $\left(\mathrm{K}^{+}\right)$contamination. ${ }^{(7,8)}$ Ethylenediamine pyrocatechol (EDP) has a moderate silicon etching rate and compatibility with integrated circuit processes, but it has high toxicity and requires special safety measures. ${ }^{(9,10)}$ Tetramethyl ammonium hydroxide (TMAH) is gaining popularity for use in MEMS because it is nontoxic and safe to handle, has a high silicon etching rate, and is compatible with the conventional MOS fabrication process, making TMAH a good choice as a silicon etchant for future MEMS products. ${ }^{(11-13)}$ Additives, such as silicic acid, ammonium peroxodisulfate $\left[\left(\mathrm{NH}_{4}\right)_{2} \mathrm{SO}_{4}\right]$, and isopropyl alcohol (IPA), may also alter the etching anisotropy. ${ }^{(14-16)} \mathrm{An}$ ordinary TMAH solution yields rough etched silicon surfaces; however, when TMAH is doped with suitable amounts of $\left(\mathrm{NH}_{4}\right)_{2} \mathrm{SO}_{4}$ and silicic acid, the mixture solution provides complete aluminum passivation as well as an increased silicon etching rate and smooth etched surfaces. ${ }^{(17,18)}$

U-grooved photodetectors may be considered as an industrial competitor to planar structure photodetectors. This study focused on improving the nanostructured silicon surface and enhancing the performance of U-grooved photodetectors by anisotropic etching methods. Etching of the electrode metal layer in an alkaline solution using a wet etching technique is required to manufacture photodetectors with an aluminum/n-Si/aluminum structure. In previous studies, silicic acid has been shown to reduce the etching rate of aluminum by as much as $80 \%$ compared with aluminum etching without silicic acid. The silicon surface becomes very rough after etching in this solution. However, a suitable amount of $\left(\mathrm{NH}_{4}\right)_{2} \mathrm{SO}_{4}$ can be utilized to obtain a smoother surface. ${ }^{(19)}$ This paper reports the results of experiments performed to compare silicon etching rates and the smoothness of the etched silicon surface for different silicon etchants, namely, pure TMAH and dual-doped TMAH solution. We report a photodetector with a new U-grooved structure as a result of developing an etching solution. The U-grooved structure has the advantage of an increased optical response due to the larger light-detecting area, and its nanostructured surface enables the device to be fabricated with several specifications at the same time. In addition, low-cost and industrial-scale production is easier using the technique.

\section{Materials and Methods}

A U-grooved metal-semiconductor-metal (UMSM) structure photodetector with aluminum/n-Si/aluminum materials in this study was fabricated on a 6-inch n-type Si (100) substrate with a thickness of $625 \mu \mathrm{m}$ and a resistivity of 5-10 $\Omega \cdot \mathrm{cm}$. The process steps are shown in Fig. 1. Initially, organic substances and metal ions on the surface of the silicon were removed in an ultrasonic bath. Then, a 1.5- $\mu \mathrm{m}$-thick aluminum (Al) layer was grown by sputtering. Next, a 15000 -Å-thick silicon dioxide $\left(\mathrm{SiO}_{2}\right)$ layer was deposited by plasma-enhanced chemical vapor deposition (PE-CVD). After that, the textured silicon surface of the photodetector was exposed by photolithography as shown in Fig. 2.

The silicon surface was prepared by an anisotropic etching process as shown in Fig. 3. The etching solutions comprised $5 \mathrm{wt} . \%$ TMAH and $34 \mathrm{~g} / 1$ silicic acid with different amounts of $\left(\mathrm{NH}_{4}\right)_{2} \mathrm{SO}_{4}(10.0,10.5,11.0,11.5,12.0,12.5$, and $13.0 \mathrm{~g} / \mathrm{l})$ at $80^{\circ} \mathrm{C}$. The solution was heated with a hot plate and stirred with a magnetic stirrer rotating at $200 \mathrm{rpm}$. 


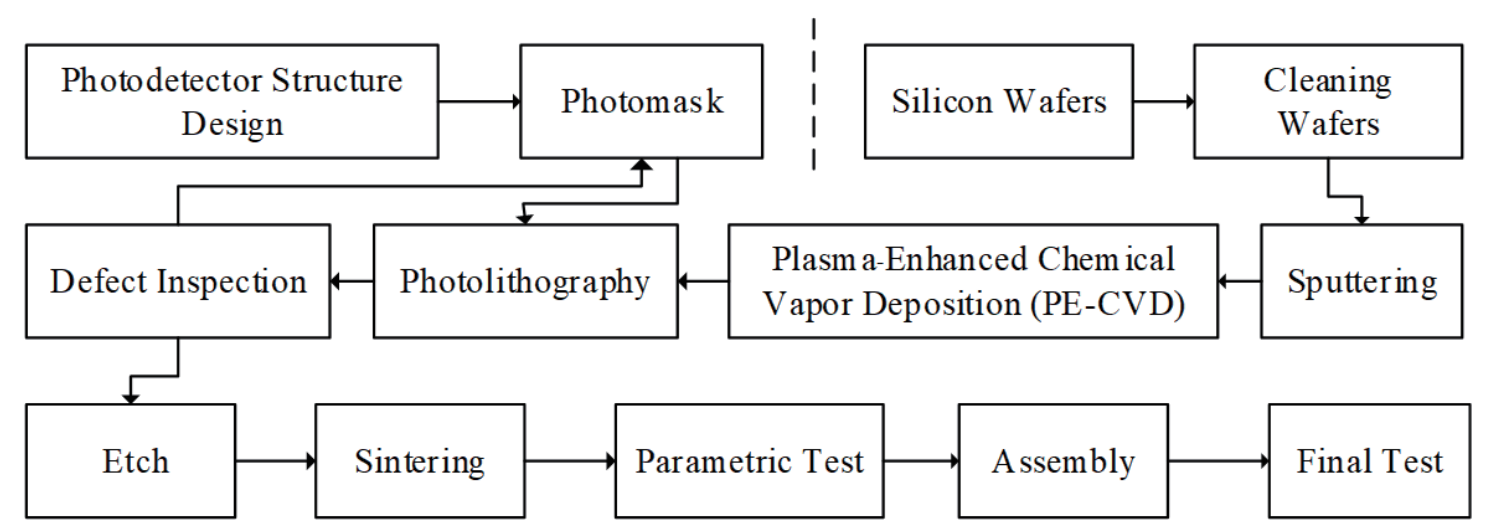

Fig. 1. Fabrication flowchart of photodetector based on silicon structure.
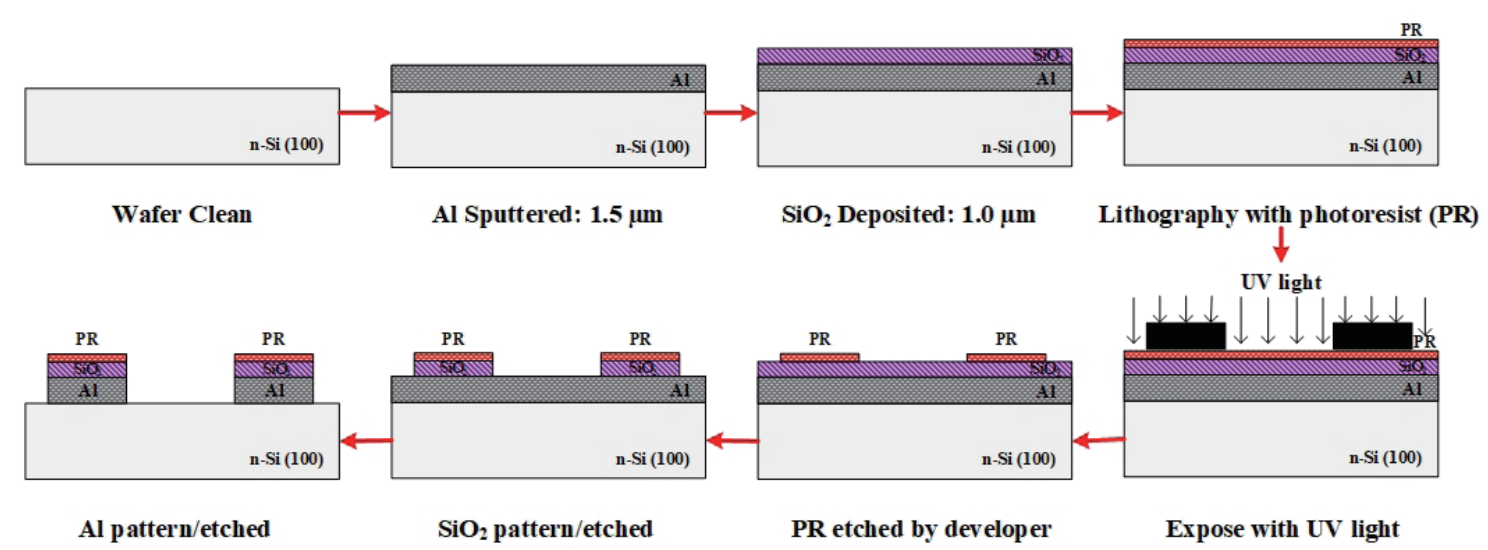

n-Si

Fig. 2. (Color online) Photolithography steps.

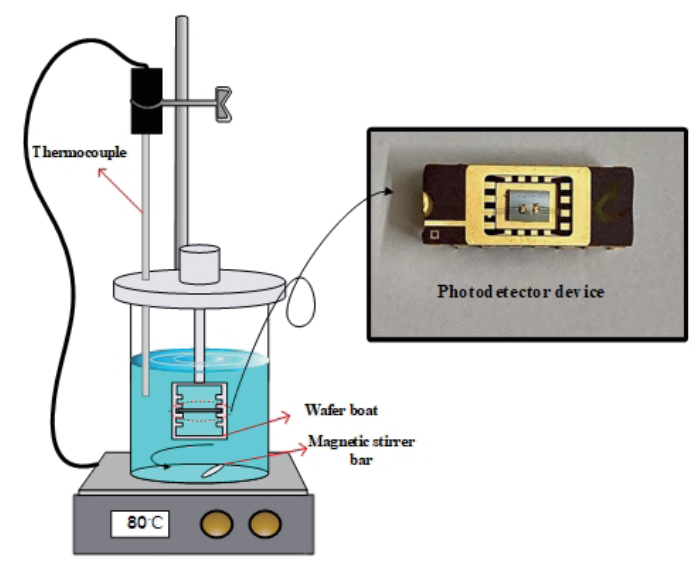

(a)

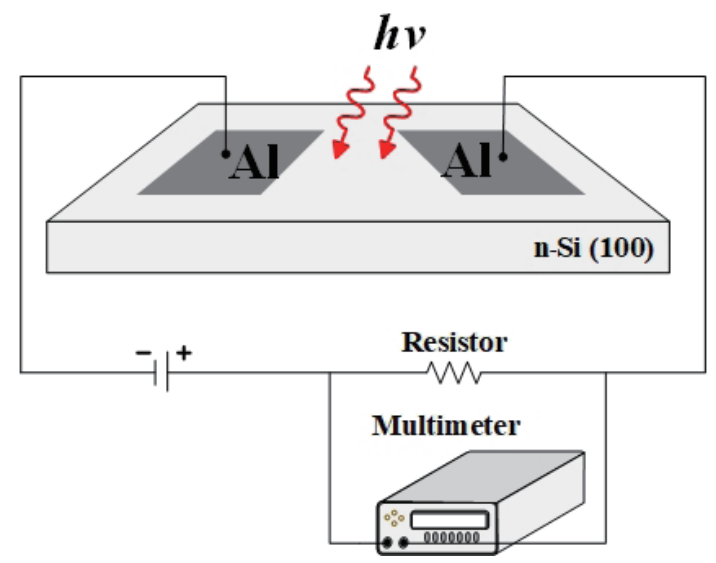

(b)

Fig. 3. (Color online) (a) Etching process and (b) 3D schematic of the photodetector measuring process. 
Finally, the silicon roughness was measured with a surface profilometer (DEP KLA-Tencor $\mathrm{P} 10)$, the microscopic structure of the $\mathrm{Si}$ surface was investigated with an atomic force microscope (AFM), and a scanning electron microscope (SEM) was utilized to characterize the surface morphology and measure the etching depth. The optical and electrical properties of samples were investigated using a Cascade Microtech M150 probe station, using a light source with a wavelength of $635 \mathrm{~nm}$.

\section{Results and Discussion}

\subsection{Physical characteristics of photodetector}

The silicon surface was etched by anisotropic etching in TMAH (5 wt.\%) and silicic acid (34 g/l) with different amounts of $\left(\mathrm{NH}_{4}\right)_{2} \mathrm{SO}_{4}(10.0-13.0 \mathrm{~g} / \mathrm{l})$, and the surface roughness and etching rate parameters were measured using a surface profilometer (DEP KLA-Tencor P10). A previous study of Suttijalern et al. ${ }^{(7)}$ found that the average surface roughness of $5 \mathrm{wt} . \% \mathrm{TMAH}$ solution with $34 \mathrm{~g} / 1$ silicic acid was $2730 \mathrm{~nm}$ at $80{ }^{\circ} \mathrm{C}$. When we added $11.5 \mathrm{~g} / 1\left(\mathrm{NH}_{4}\right)_{2} \mathrm{SO}_{4}$ to $5 \mathrm{wt} . \%$ TMAH solution with $34 \mathrm{~g} / 1$ silicic acid, the estimated roughness of the smooth area was less than $11.1 \mathrm{~nm}$. As shown in Table 1, 5 wt.\% TMAH with $34 \mathrm{wt} \%$ silicic acid solution had a significantly lower aluminum etching rate than 5 wt.\% TMAH. However, etching in $5 \mathrm{wt} . \%$ TMAH and $34 \mathrm{wt} . \%$ silicic acid solution resulted in a high silicon surface roughness. In this work, the optimum amount of $\left(\mathrm{NH}_{4}\right)_{2} \mathrm{SO}_{4}$ for reducing silicon roughness was studied. The results showed that using $5 \mathrm{wt} \%$ TMAH with $34 \mathrm{wt} \% \%$ silicic acid and $11.5 \mathrm{~g} / 1\left(\mathrm{NH}_{4}\right)_{2} \mathrm{SO}_{4}$ reduced the silicon surface roughness as well as the aluminum etching rate.

As shown in Fig. 4, it was found that the addition of $10.0 \mathrm{~g} / 1\left(\mathrm{NH}_{4}\right)_{2} \mathrm{SO}_{4}$ resulted in a silicon surface roughness of $343.1 \mathrm{~nm}$. The silicon surface roughness first decreased and then increased with increasing amount of $\left(\mathrm{NH}_{4}\right)_{2} \mathrm{SO}_{4}(>11.5 \mathrm{~g} / \mathrm{l})$. The increased roughness of the silicon surface after etching was due to an over-replenishing effect that reduces the oxidizing ability of $\left(\mathrm{NH}_{4}\right)_{2} \mathrm{SO}_{4}$, resulting in its slower decomposition. The decomposition of $\left(\mathrm{NH}_{4}\right)_{2} \mathrm{SO}_{4}$ was also observed during the wet etching process through the monotonic decrease in the $\mathrm{Si}(100)$ etching rate with over-etching time. ${ }^{(20)}$

The enhanced etching selectivity of TMAH/silicic acid solution in the etching of silicon can be improved by doping the solution with $\left(\mathrm{NH}_{4}\right)_{2} \mathrm{SO}_{4}$. The silicon etching rate was increased by adding $\left(\mathrm{NH}_{4}\right)_{2} \mathrm{SO}_{4}$ as shown in Fig. 4, with the etching rate changing linearly with the amount of

Table 1

Variation of etching rate and surface roughness with etching conditions.

\begin{tabular}{lccccc}
\hline Case & TMAH solution & $\begin{array}{c}\text { Si etching rate } \\
(\mu \mathrm{m} / \mathrm{min})\end{array}$ & $\begin{array}{c}\text { Al etching } \\
\text { rate }(\mu \mathrm{m} / \mathrm{h})\end{array}$ & $\begin{array}{c}\text { Si roughness } \\
(\mathrm{nm})\end{array}$ & Ref. \\
\hline 1 & $5 \mathrm{wt} . \%$ & 0.68 & 114.06 & 420 & $(7)$ \\
\hline 2 & $5 \mathrm{wt} \%+34 \mathrm{~g} / \mathrm{l}$ silicic acid & 0.15 & 0.145 & 2730 & $(7)$ \\
\hline 3 & $\begin{array}{c}5 \mathrm{wt} \%+34 \mathrm{~g} / \mathrm{l} \text { silicic acid } \\
+10 \mathrm{~g} / 1(\mathrm{NH})_{4} \mathrm{SO}_{4}\end{array}$ & 0.61 & 0.159 & 343.1 & This work \\
\hline 4 & $\begin{array}{c}5 \mathrm{wt} \%+34 \mathrm{~g} / \mathrm{l} \mathrm{silicic} \mathrm{acid} \\
+11.5 \mathrm{~g} / 1\left(\mathrm{NH}_{4}\right)_{2} \mathrm{SO}_{4}\end{array}$ & 1.00 & 0.17 & 11.1 & This work \\
\hline
\end{tabular}




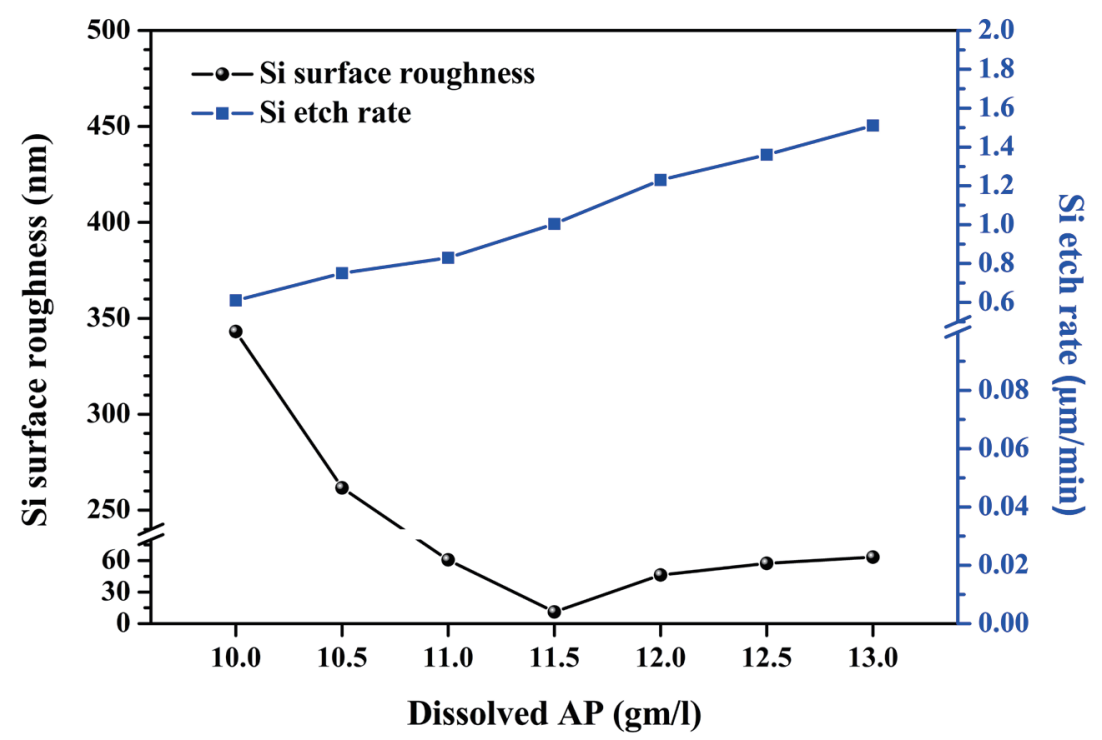

Fig. 4. (Color online) Relationship between etch rate and surface roughness of silicon (100).

dissolved $\left(\mathrm{NH}_{4}\right)_{2} \mathrm{SO}_{4}$. The dissolved $\left(\mathrm{NH}_{4}\right)_{2} \mathrm{SO}_{4}$ concentration was increased from 10.0 to $13.0 \mathrm{~g} / 1$, whereas the silicon etching rate was increased from 0.61 to $1.51 \mu \mathrm{m} / \mathrm{min}$. We assumed that adding $\left(\mathrm{NH}_{4}\right)_{2} \mathrm{SO}_{4}$ to the mixture of silicic acid and TMAH solution changed the $\mathrm{pH}$ value of the etchant. The etchant anisotropy is affected by $\mathrm{pH}$-dependent changes in the $\mathrm{OH}^{-}$ content, ${ }^{(21,22)}$ and adding an oxidizing substance such as $\left(\mathrm{NH}_{4}\right)_{2} \mathrm{SO}_{4}$ enhances the silicon etching rate. ${ }^{(12,13,23,24)}$ From the results of this experiment, the optimum replenishing concentration and etching conditions can be determined, i.e., the addition of $11.5 \mathrm{~g} / 1\left(\mathrm{NH}_{4}\right)_{2} \mathrm{SO}_{4}$ to TMAH (5 wt.\%) with silicic acid ( $34 \mathrm{~g} / \mathrm{l})$ solution (also called the dual-doped TMAH) enables the fabrication of a U-grooved photodetector.

We investigated the silicon and aluminum etching rates in the dual-doped TMAH solution. The graphs obtained were approximately linear, with the silicon etching rate increasing with etching time, as shown in Fig. 5. The aluminum etching rate shows the same tendency as the silicon etching rate, with etching rates of $1.0 \mu \mathrm{m} / \mathrm{min}$ and $0.17 \mu \mathrm{m} / \mathrm{h}$, respectively. The dualdoped TMAH solution was found to prevent aluminum etching due to the formation of a siliconrich oxide (SRO) layer on the $\mathrm{Al}$ layer in the presence of the oxidizing agents $\left(\mathrm{NH}_{4}\right)_{2} \mathrm{SO}_{4}$ and $\mathrm{H}_{4} \mathrm{SiO}_{4} \cdot{ }^{(25)}$

The dual-doped TMAH solution has a lower etching rate on aluminum because the oxide layer contains amphoteric $\mathrm{Al}(\mathrm{OH})_{3}$, which reacts in alkaline solutions to form aluminate as follows. ${ }^{(11)}$

$$
\mathrm{Al}(\mathrm{OH})_{3}+\mathrm{OH}^{-} \leftrightarrow \mathrm{Al}(\mathrm{OH})_{4}^{-}
$$

The $\mathrm{pH}$ value is reduced by the addition of silicic acid, shifting the chemical equilibrium to the left side of the reaction equation. It was previously found that the aluminum etching rate may 


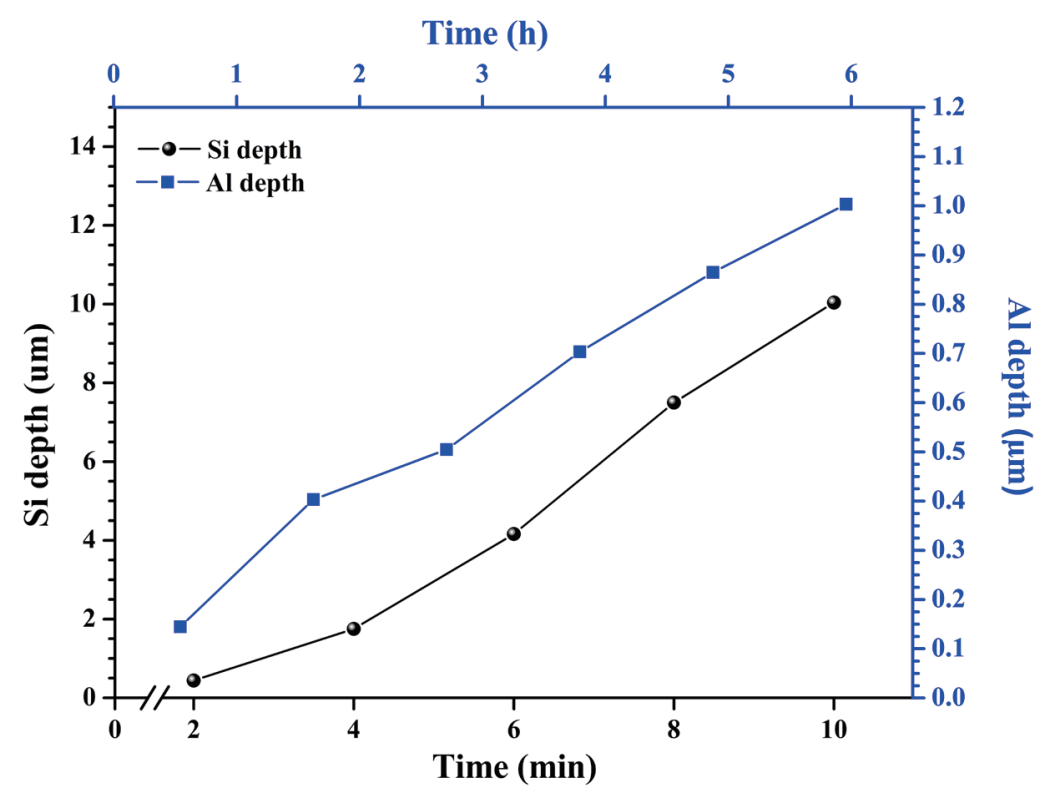

Fig. 5. (Color online) Relationship between etching depths of silicon and aluminum and etching time.

be reduced by two orders of magnitude by doping etchants with acid to lower the $\mathrm{pH} .{ }^{(26)}$ The chemical reaction rate of the aluminum layer in the TMAH solution is decreased by doping the solutions with silicic acid. This is due to the formation of a protective layer on the aluminum surface, and the silicates in the solution react with $\mathrm{Al}(\mathrm{OH})_{3}$ to form sparingly soluble pyrophyllite-type silicates, which passivate the aluminum surface. ${ }^{(27-30)}$

We studied the characteristics of the silicon surface etched under different conditions using a SEM operated at $5.0 \mathrm{kV}$ and $30000 \times$ magnification. Figure 6(a) shows that the silicon surface after etching in a $5 \mathrm{wt} . \%$ TMAH solution is rough with random pyramids of approximately $600 \mathrm{~nm}$ size. This roughness is caused by the concentration of the solution, uneven etching direction, and bubbles that develop on the etched surface. As shown in Fig. 6(b), the average width of a random pyramid of a dual-doped TMAH solution is $15 \mathrm{~nm}$. When the concentration of $\left(\mathrm{NH}_{4}\right)_{2} \mathrm{SO}_{4}$ is increased, the etched surface roughness becomes less than that in the pure TMAH solution. This is because the oxygen in $\left(\mathrm{NH}_{4}\right)_{2} \mathrm{SO}_{4}$ oxidizes silicon more strongly than water, and therefore becomes the major oxidizing agent of silicon during the etching process. The oxidizing agent affects the smoothness of the silicon surface because it removes the surface. Figure 6(c) shows the photodetector cross section of the U-grooved structure with a wide distance between the electrodes, which was fabricated using a dual-doped TMAH solution. The aluminum electrodes were not damaged as a result of the etching process.

An AFM was used to analyze the nano-morphology on the silicon surface after etching. Figure 7 shows AFM images of the morphology of the Si (100) surface after etching in dualdoped TMAH for about 4 min. It was found that the silicon surface has a roughness of about $11.1 \mathrm{~nm}$. For optimization, it is essential to clarify the reduction of the silicon roughness upon adding $\left(\mathrm{NH}_{4}\right)_{2} \mathrm{SO}_{4}$ to the TMAH solution with silicic acid. $\left(\mathrm{NH}_{4}\right)_{2} \mathrm{SO}_{4}$ is an oxidizer used to control the problem of hillock formation in low-concentration TMAH to prevent the depletion of 


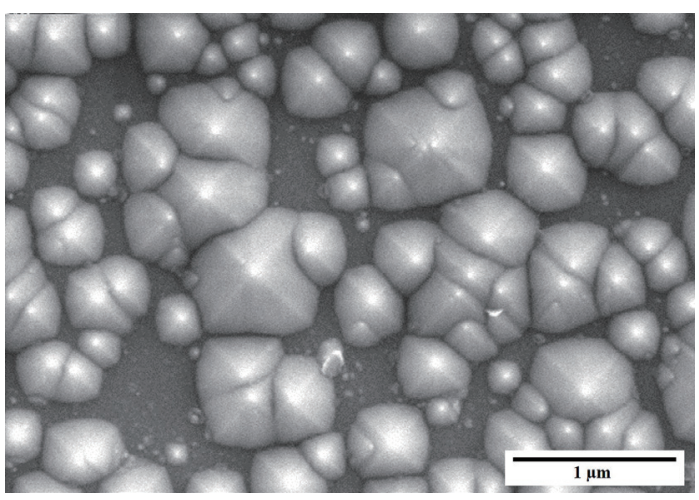

(a)

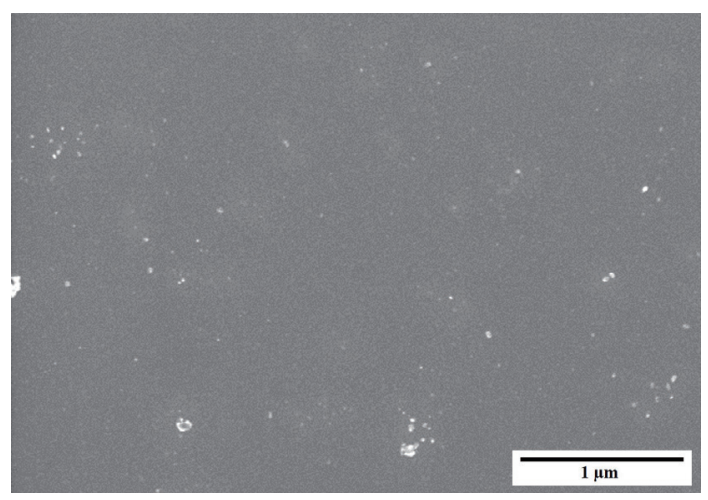

(b)

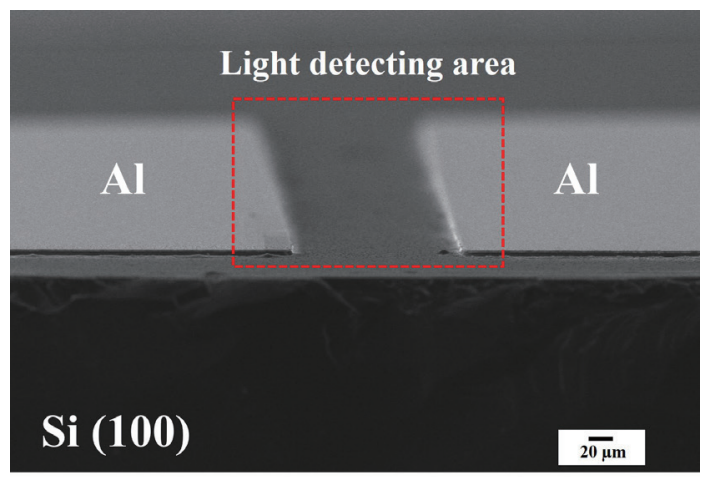

(c)

Fig. 6. (Color online) SEM images of the silicon surface after etching in (a) $5 \mathrm{wt}$ \% TMAH solution and (b) dualdoped TMAH solution. (c) Cross section of a UMSM photodetector after etching in dual-doped TMAH solution.
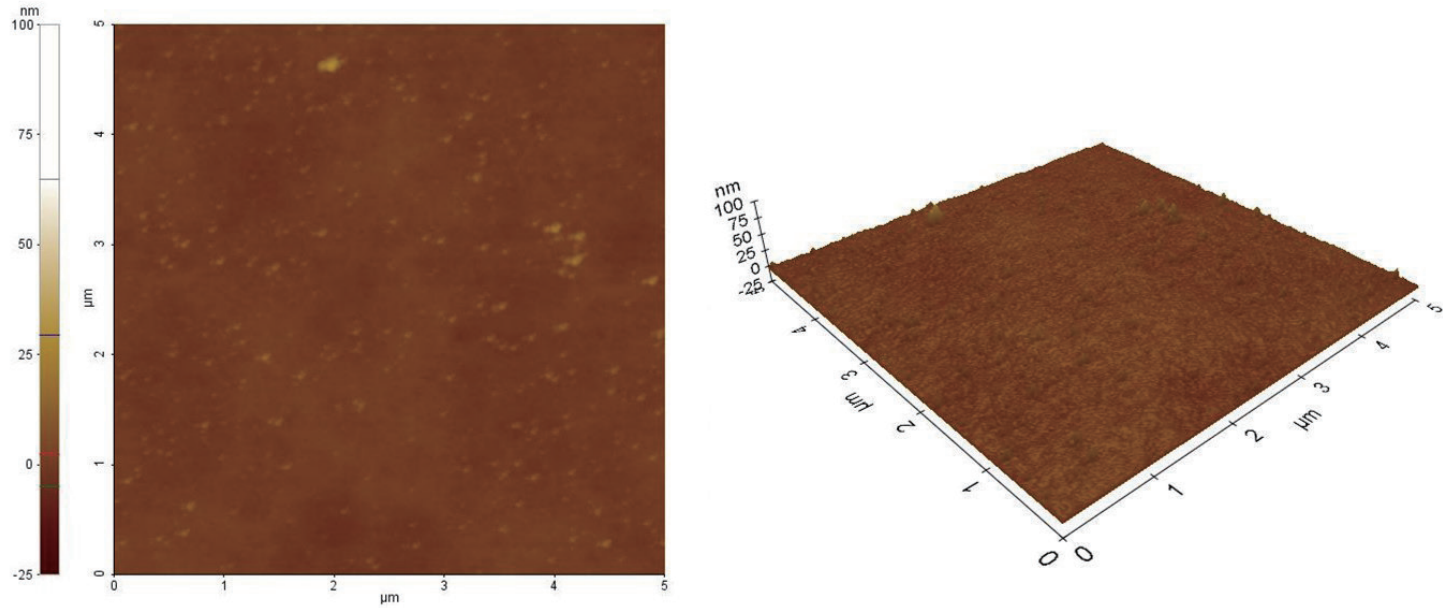

Fig. 7. (Color online) AFM images of $\mathrm{Si}$ (100) surface after etching in dual-doped TMAH solution.

the oxidizer during the etching process. $\left(\mathrm{NH}_{4}\right)_{2} \mathrm{SO}_{4}$ appears to reduce the size of the bubbles that form, therefore reducing their dwell time on the silicon surface, resulting in a micromasking effect. $^{(12,31-33)}$ The dual-doped TMAH solution has potential use for developing photodetectors with a larger exposure area. 


\subsection{Optical and electrical characteristics of photodetector}

The electrical characteristics of photodetectors with a U-grooved structure made of aluminum/n-Si/aluminum, as well as those with a wide distance between the electrodes (wide electrode gap), were investigated. We fabricated a UMSM photodetector using the anisotropic etching process. The electrical properties of the photodetector were measured under dark and illuminated conditions using halogen lamps as a light source, and the bias voltage was varied from -5 to $5 \mathrm{~V}$. A block diagram of the experimental setup is shown in Fig. 8.

The photodetector structure can be described by two back-to-back Schottky contacts. Figure 9 shows the current-voltage $(I-V)$ characteristics of the metal-semiconductor-metal (MSM) and UMSM photodetectors. According to the results, the UMSM photodetector fabricated using a dual-doped TMAH solution had a dark current of $0.14 \mu \mathrm{A}$, which was slightly higher than that of $0.10 \mu \mathrm{A}$ for the MSM photodetector. The photodetectors were evaluated using a halogen lamp at an illumination of 25000 lux. In a typical test, when a bias was applied at both electrodes of the photodetector, a depletion region was formed, and at a constant voltage of $5 \mathrm{~V}$, the depletion region extended to about $4 \mu \mathrm{m}$. When the light-detecting area of the MSM
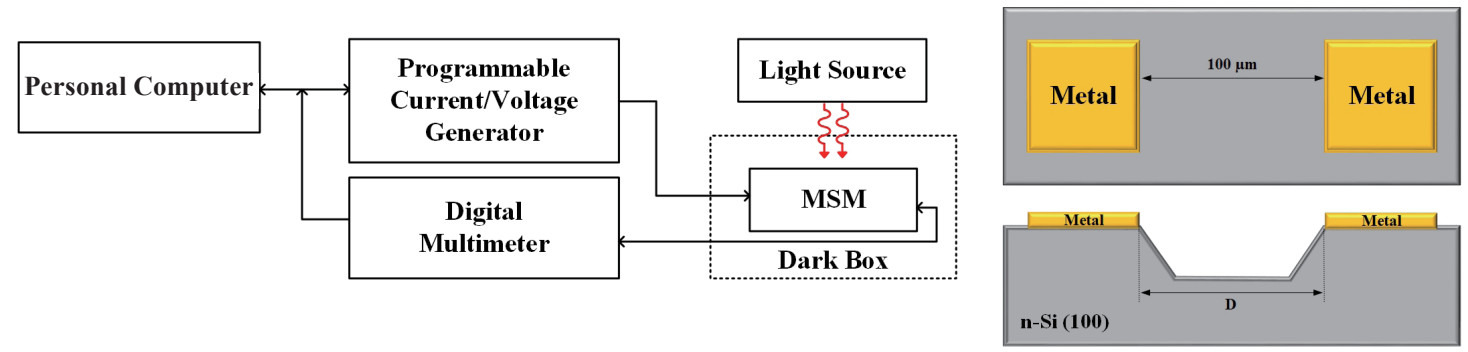

Fig. 8. (Color online) Block diagram of the experimental setup used to measure the electrical properties of the photodetector.

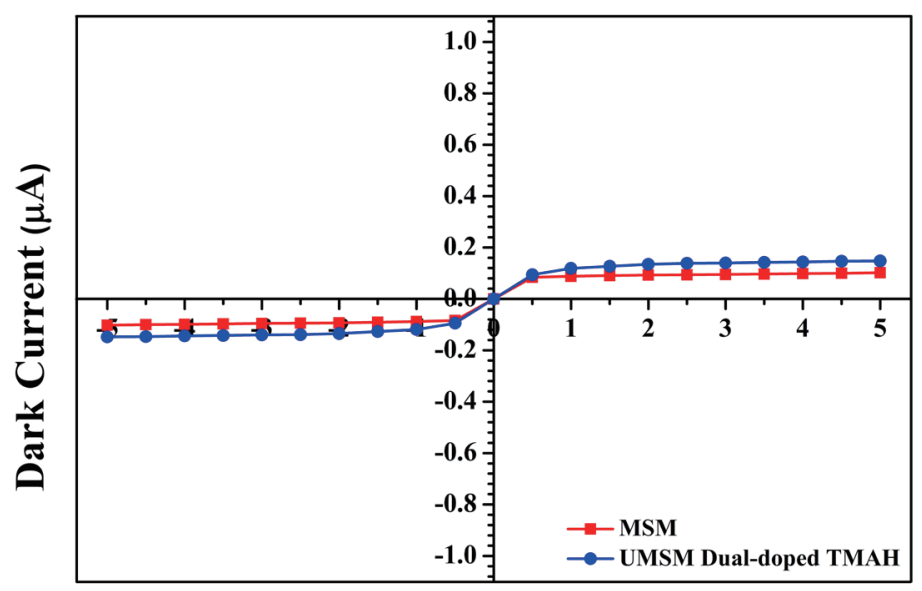

Bias Voltage (V)

Fig. 9. (Color online) Electrical characteristics of MSM and UMSM photodetectors under non-illuminated condition. 
photodetector was exposed to light, the photocurrent was $21.51 \mu \mathrm{A}$ (Fig. 10). The UMSM photodetector fabricated in the dual-doped TMAH exhibited a photocurrent of $49.43 \mu \mathrm{A}$, approximately twice that of the MSM photodetector. Increasing the light-detecting area in the U-grooved structure resulted in a significant increase in the photocurrent. ${ }^{(34)}$

Figure 11 shows $I-V$ plots obtained with a laser diode (wavelength $635 \mathrm{~nm}$ ). It can be seen that the UMSM photodetector is capable of responding to direct current (DC). The dark current $(\sim 0.14 \mu \mathrm{A})$ is very low. The photocurrent increases with increasing incident optical power, and the photo-to-dark current ratio is approximately 500 at an incident optical power of $6 \mathrm{~mW}$. The high photocurrent of the UMSM photodetector is mainly due to the large light-detecting area

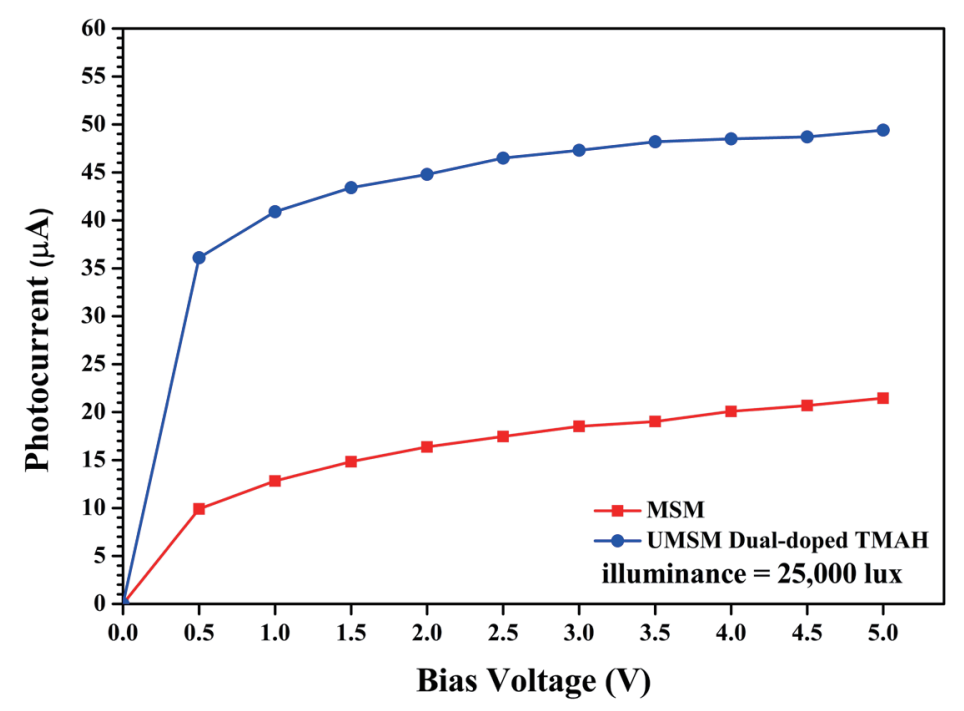

Fig. 10. (Color online) Electrical characteristics of MSM and UMSM photodetectors illuminated with light of 25000 lux.

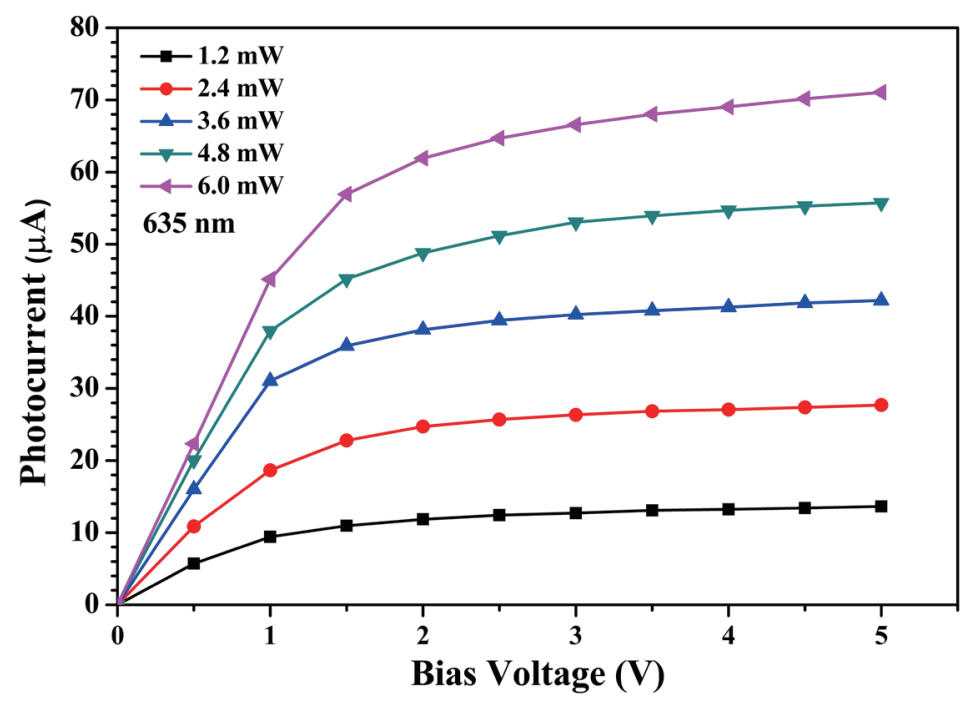

Fig. 11. (Color online) $I-V$ characteristics of UMSM photodetector fabricated in dual-doped TMAH under various incident optical powers. 
resulting from the etched U-grooved structure and because the photodetector is operated under reverse bias. As previously mentioned, the U-grooved photodetector characteristics can be used as a measurement of light intensity, even when little light is incident on the photodetector.

The capacitance-voltage $(C-V)$ curves of aluminum/n-Si/aluminum photodetectors are symmetrical, with the capacitance decreasing with increased bias voltage (Fig. 12). The total capacitance $\left(C_{T}\right)$ is equal to the sum of the capacitances of two contacts, i.e., the cathode capacitance $\left(C_{C}\right)$ under reverse bias voltage and the anode capacitance $\left(C_{A}\right)$ under forward bias voltage. At a frequency of $100 \mathrm{kHz}$ and $5 \mathrm{~V}$ bias, the capacitance of the photodetector with the U-grooved structure was $6.76 \mathrm{pF}$, compared with $13.52 \mathrm{pF}$ for the planar structure. The area lost to etching relative to the capacitance of the U-grooved photodetector is low. The capacitance is directly proportional to the diffused area and inversely proportional to the width of the depletion region. The capacitance is dependent on the reverse bias as follows:

$$
C=\frac{\varepsilon_{S} A}{\sqrt{2 \varepsilon_{s} \mu \rho\left(V_{b i}+V_{A}\right)}}=\frac{\varepsilon_{s} A}{W_{d}}
$$

where $\varepsilon_{S}$ is the semiconductor permittivity $\left(1.054 \times 10^{-12} \mathrm{~F} / \mathrm{cm}\right), A$ is the photodetector area, $\rho$ is the resistivity of silicon, $\mu$ is the mobility of the electrons at $300 \mathrm{~K}\left(1400 \mathrm{~cm}^{2} / \mathrm{Vs}\right), V_{A}$ is the applied bias, $V_{b i}$ is the built-in voltage, and $W_{d}$ is the width of the depletion region. The depletion width determines the capacitance of the photodetector according to this equation. The capacitance of the UMSM photodetector is decreased when the depth of the U-grooved structure is substantially eliminated after etching, which has the benefits of lower capacitance and enhanced frequency response of the UMSM photodetector.

The two photodetectors were measured at an incident optical power of $6 \mathrm{~mW}$. The photocurrent corresponds to the responsivity of the photodetector $R=\left(I_{\text {photo }}-I_{\text {dark }}\right) / P_{\text {in }}$, where $R$ is the responsivity, $I_{\text {photo }}$ and $I_{\text {dark }}$ are photocurrents, and $P_{\text {in }}$ is the incident optical power.

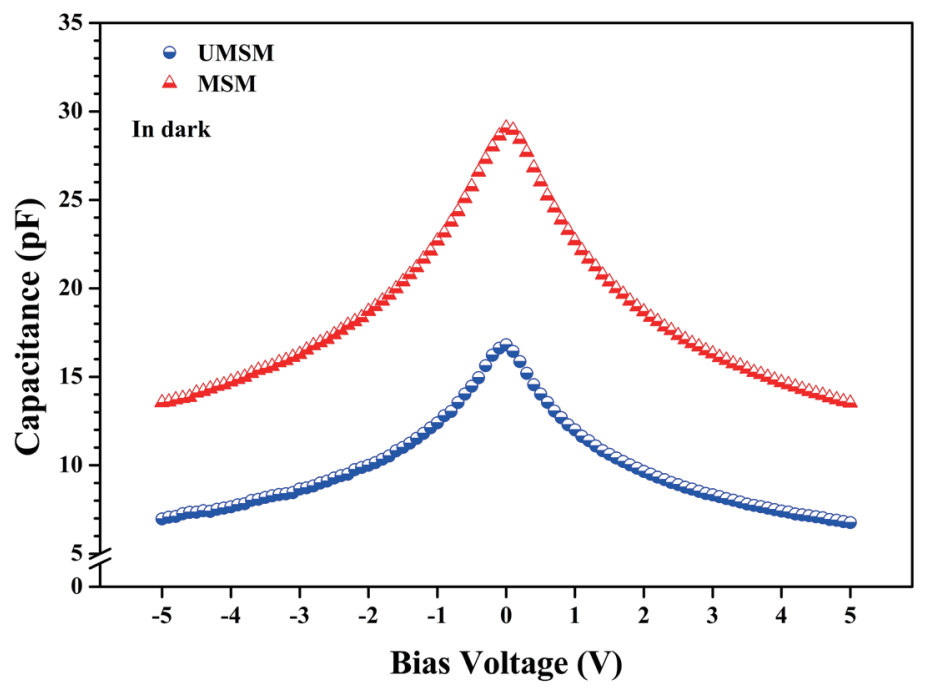

Fig. 12. (Color online) $C-V$ characteristics of MSM and UMSM photodetectors. 
Figure 13 shows that the responsivity increases with increasing applied bias. The U-grooved photodetector fabricated by wet etching in dual-doped TMAH has a higher responsivity, $11.84 \mathrm{~mA} / \mathrm{W}$, at a wavelength of $635 \mathrm{~nm}$ than that of the MSM photodetector. The external quantum efficiency (EQE) of the two photodetectors has the same tendency as the responsivity. The EQE of the MSM photodetector was found to be $0.94 \%$ for the $635 \mathrm{~nm}$ incident laser. In contrast, that of the UMSM photodetector under the dual-doped TMAH condition was $2.31 \%$, almost 2.5 times that of the MSM photodetector. The U-grooved structure photodetector exhibits a much higher performance because the large light-detecting surface area increases the number of photogenerated carriers at the surface of the U-grooved structure, preventing charge-carrier recombination. ${ }^{(30,35,36)}$ Table 2 shows a comparison of the important parameters of the MSM and UMSM photodetectors. It was found that the electrical and optical properties of the UMSM photodetector were superior to those of the MSM photodetector of the same size: at an incident optical power of $6 \mathrm{~mW}$, the UMSM photodetector had a photocurrent of $71.05 \mu \mathrm{A}$, approximately 2.5 times more than that of the MSM photodetector $(28.92 \mu \mathrm{A})$. The key advantages of UMSM photodetectors include higher photocurrent and responsivity, lower capacitance, and greater light-detecting area than those of a conventional MSM photodetector. These results suggest that this new U-grooved photodetector has potential use in optical electronics.

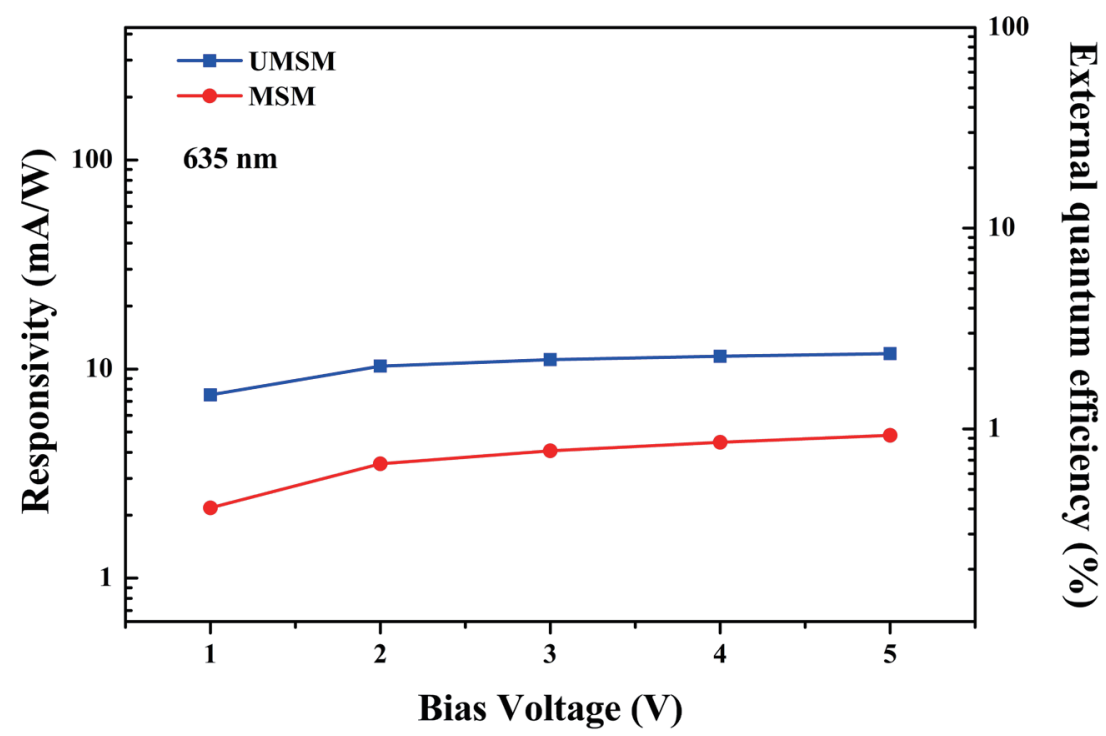

Fig. 13. (Color online) Dependence of maximum responsivity and EQE of MSM and UMSM photodetectors on external bias.

Table 2

Characteristics of MSM and UMSM photodetectors at bias voltage of $5 \mathrm{~V}$.

\begin{tabular}{lccccc}
\hline $\begin{array}{l}\text { Structure of } \\
\text { photodetector }\end{array}$ & $\begin{array}{c}\text { Dark current } \\
(\mu \mathrm{A})\end{array}$ & $\begin{array}{c}\text { Photocurrent } \\
(\mu \mathrm{A})\end{array}$ & $\begin{array}{c}\text { Capacitance } \\
(\mathrm{pF})\end{array}$ & $\begin{array}{c}\text { Responsivity } \\
(\mathrm{mA} / \mathrm{W})\end{array}$ & $\begin{array}{c}\text { EQE } \\
(\%)\end{array}$ \\
\hline MSM & 0.10 & 28.92 & 13.52 & 4.82 & 0.94 \\
\hline UMSM & 0.14 & 71.05 & 6.76 & 11.84 & 2.31 \\
\hline
\end{tabular}




\section{Conclusions}

An experimental study on silicon surface etching by an anisotropic wet chemical process in TMAH etchant was carried out. The nanostructure in a U-grooved photodetector based on $\mathrm{Si}$ (100) was successfully fabricated with a smoothness of about $11.1 \mathrm{~nm}$ in a mixture of TMAH solution and silicic acid with $11.5 \mathrm{~g} / 1\left(\mathrm{NH}_{4}\right)_{2} \mathrm{SO}_{4}$ added (dual-doped TMAH), without the etching of the aluminum electrodes. In terms of electric properties, the photocurrent of the UMSM photodetector was $59 \%$ ( 2.5 times) more than that of the MSM photodetector under $635 \mathrm{~nm}$ laser illumination. The capacitance of the U-grooved structure etched with a dual-doped TMAH solution was about twice that of the planar structure. The structural design inside the lightdetecting area has the potential to further improve the optical response of the photodetector by creating the U-grooved interdigitated structure.

\section{Acknowledgments}

This work was supported by King Mongkut's Institute of Technology Ladkrabang under Scholarship Number KDS 2019/017. We would like to thank the Thai Microelectronics Center (TMEC) for the silicon wafer fabrication and the Electronics Research Center (ERC) for providing the laboratory for this research.

\section{References}

1 J. A. Dziuban and R. Walczak: Sens. Mater. 13 (2001) 41.

2 H. H. Lee, S.-H. Jo, M. Bae, B.-S. Choi, J. Kim, H.-K. Lyu, and J.-K. Shin: Sens. Mater. 27 (2015) 135.

3 H. Chen, M. Xue, Z. Mei, S. B. Oetomo, and W. Chen: Sensors 16 (2016) 1. https://doi.org/10.3390/s16122134

4 J.-J. Tsaur, S.-I Yang, C.-H. Du, Z. Lin, C.-T. Huang, and C.-K. Lee: J. Micromech. Microeng. 4174 (2000) 142. https://doi.org/10.1117/12.396424

5 K. Biswas, S. Das, D. K. Maurya, S. Kal, and S. K. Lahiri: Microelectron. J. 37 (2006) 321. https://doi. org/10.1016/j.mejo.2005.05.013

6 S.-H. Seo, K.-D. Kim, M.-W. Seo, J.-S. Kong, J.-K. Shin, and P. Choi: Sens. Mater. 19 (2007) 435.

7 K. Suttijalern, J. Prabket, R. Muanghlua, and S. Niemcharoen: Proc. 7th Int. Electrical Engineering Congr. (iEECON, 2019). 61. https://doi.org/10.1109/iEECON45304.2019.8939006

8 V. Karanassios and G. Mew: Sens. Mater. 9 (1997) 395.

9 S. D. Hutagalung and K. C. Lew: Proc. 2010 IEEE Int. Conf. Semiconductor Electronics (IEEE, 2010) 358. https://doi.org/10.1109/SMELEC.2010.5549507

10 O. Tabata, R. Asahi, H. Funabashi, K. Shimaoka, and S. Sugiyama: Sens. Actuators, A 34 (1992) 51. https://doi. org/10.1016/0924-4247(92)80139-t

11 U. Schakenberg, W. Benecke, and P. Lange: Proc. 1991 Int. Conf. Solid-State Sensors and Actuators. Digest of Technical Papers (1991) 815. https://doi.org/10.1109/SENSOR.1991.149008

12 K. Biswas, S. Das, D. K. Maurya, S. Kal, and S. K. Lahiri: Microelectron. J. 37 (2006) 321. https://doi. org/10.1016/j.mejo.2005.05.013

13 J. T. L. Thong, W. K. Choi, and C. W. Chong: Sens. Actuators, A 63 (1997) 243. https://doi.org/10.1016/S09244247(97)80511-0

14 K. Suttijalern, J. Prabket and S. Niemcharoen: Proc. The 2018 IAENG Int. Conf. Engineering Physics (2018) 76.

15 D. Cheng, M. A. Gosálvez, T. Hori, K. Sato, and M. Shikida: Sens. Actuators, A 125 (2006) 415. https://doi.org/ https://doi.org/10.1016/j.sna.2005.08.022

16 G.-S. Chung, W.-J. Lee, and J.-S. Song: Sens. Mater. 12 (2000) 221.

17 K. Biswas and S. Kal: Microelectron. J. 37 (2006) 519. https://doi.org/10.1016/j.mejo.2005.07.012

18 S. B. Lee and D. Babić: J. Electrochem. Soc. 146 (1999) 4213. https://doi.org/10.1149/1.1392616 
19 M. Sasaki, T. Fujii, and K. Hane: Sens. Mater. 15 (2003) 083.

20 J.-H. Kim, Y.-M. Jung, Y.-J. Cho, J.-W. Kim, Y.-C. Kim, H.-I. Seo, K.-H. Kim, and M. Ishida: Sens. Mater. 18 (2006) 125 .

21 B. K. Sivertsex and H. Serrum: J. Micromech. Microeng. 130 (1969) 449. https://doi.org/10.1524/ zkri.1969.130.1-6.449

22 M. A. Gosalvez, A. S. Foster, and R. M. Nieminen: Sens. Mater. 15 (2003) 053.

23 O. Tabata: Sens. Actuators, A 53 (1996) 335. https://doi.org/10.1016/0924-4247(96)80157-9

24 J.-J. Tsaur, C.-H. Du, and C. Lee: Sens. Actuators, A 92 (2001) 375. https://doi.org/10.1016/S0924$\underline{4247(01) 00575-1}$

25 K. Suttijalern and S. Niemcharoen: J. Micromech. Microeng. 31 (2021) 085007. https://doi.org/10.1088/13616439/ac0e7e

26 N. Fujitsuka, K. Hamaguchi, H. Funabashi, E. Kawasaki, and T. Fukada: R\&D Review of Toyata CRDL 39 (2004) 34.

27 D. Chen, S. Liu, J. Liang, X. W. Hou, B. Guo, S. L. Yang, and H. Lv: J. Nanoeng. Nanosyst. 229 (2015) 136. https://doi.org/10.1177/1740349914528689

28 E. H. Klaassen: Micromachined Instrumentation Systems (Stanford University, California, 1996) Chap. 2.

29 U. Schnakenberg, W. Benecke, and B. Löchel: Sens. Actuators, A 23 (1990) 1031. https://doi.org/10.1016/0924$\underline{4247(90) 87084-\mathrm{V}}$

30 J.P. Kar, G. Bose, S. Tuli, A. Dangwal, and S. Mukherjee: J. Mater. Eng. Perform. 18 (2009) 1046. https://doi. org/10.1007/s11665-008-9350-1

31 D. Resnik, D Vrtacnik, U Aljancic, and S Amon: J. Micromech. Microeng. 13 (2003) 26. https://doi. org/10.1088/0960-1317/13/1/304

32 K. Suttijalern, J. Prabket, and S. Niemcharoen: Proc. Int. MultiConf. Engineers and Computer Scientists (2019) 330 .

33 J. Garra, S. Brida, L. Ferrario, and M. Paranjape: Sens. Mater. 13 (2001) 351.

34 W.-R. Lee, H. Ko, D.-I. "Dan" Cho, K.-I. Koo, and J.-M. Seo: Sens. Mater. 27 (2015) 465. https://doi. org/10.18494/SAM.2015.1084

35 J.-S. Huang, K.-W. Lee, C.-Y. Huang, and S.-F. Wang: Sens. Mater. 30 (2018) 925. https://doi.org/10.18494/ SAM.2018.1795

36 K.-T. Liu, S.-J. Chang, and S. Wu: Sens. Mater. 29 (2017) 363. https://doi.org/10.1007/s11665-008-9350-1

\section{About the Authors}

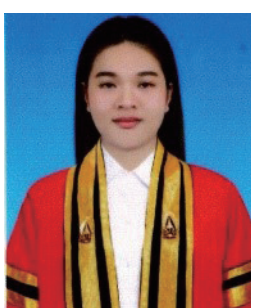

Kamonwan Suttijalern received her B.S. and M.S. degrees from King Mongkut's Institute of Technology Ladkrabang, Bangkok, Thailand, in 2016 and 2018, respectively. Since 2018, she has been studying toward a Ph.D. degree at King Mongkut's Institute of Technology Ladkrabang. Her research interests are silicon photodetectors and semiconductor fabrication processes. (ksuttijalern@gmail.com)

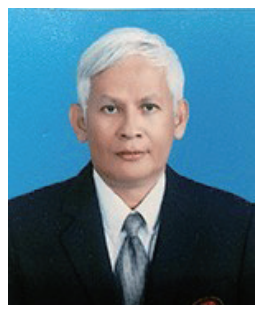

Surasak Niemcharoen received his B.S. degree from Chiang Mai University, Thailand, in 1985 and his M.S. and Ph.D. degrees from King Mongkut's Institute of Technology Ladkrabang, Bangkok, Thailand, in 1992 and 2004, respectively. Since 2015, he has been an associate professor at King Mongkut's Institute of Technology Ladkrabang. His research interests are in sensors, MEMS, CMOS technology, and MSM photodetector fabrication processes. (surasuk.ni@kmitl.ac.th) 